\title{
Twenty-five years since the identification of the first SCA gene: history, clinical features and perspectives for SCA1
}

Vinte e cinco anos desde a identificação do primeiro gene das SCAs: história, aspectos clínicos e perspectivas para a SCA1

Carlos Roberto Martins Junior', Fabrício Castro de Borba ${ }^{1}$, Alberto Rolim Muro Martinez', Thiago Junqueira Ribeiro de Rezende', Iscia Lopes Cendes², José Luiz Pedroso³, Orlando Graziani Povoas Barsottini³, Marcondes Cavalcante França Júnior ${ }^{1}$

\begin{abstract}
Spinocerebellar ataxias (SCA) are a clinically and genetically heterogeneous group of monogenic diseases that share ataxia and autosomal dominant inheritance as the core features. An important proportion of SCAs are caused by CAG trinucleotide repeat expansions in the coding region of different genes. In addition to genetic heterogeneity, clinical features transcend motor symptoms, including cognitive, electrophysiological and imaging aspects. Despite all the progress in the past 25 years, the mechanisms that determine how neuronal death is mediated by these unstable expansions are still unclear. The aim of this article is to review, from an historical point of view, the first CAG-related ataxia to be genetically described: SCA 1.
\end{abstract}

Keywords: Spinocerebellar ataxias; ataxin 1; spinocerebellar degenerations.

\section{RESUMO}

As ataxias espinocerebelares (SCA) são um grupo clínico e geneticamente heterogêneo de doenças monogênicas que compartilham ataxia e herança autossômica dominante como características principais. Uma proporção importante de SCAs é causada por expansões de repetição de trinucleotídeos CAG na região de codificação de diferentes genes. Além da heterogeneidade genética, os aspectos clínicos transcendem os sintomas motores, incluindo aspectos cognitivos, eletrofisiológicos e de imagem. Apesar de todo o progresso feito nos últimos 25 anos, os mecanismos que determinam como se dá a morte neuronal mediada por essas expansões instáveis ainda não estão claros. 0 objetivo deste artigo é revisar, de um ponto de vista histórico, a primeira ataxia geneticamente relacionada com o CAG descrita: SCA 1.

Palavras-chave: ataxias espinocerebelares; ataxina 1; degenerações espinocerebelares.

\section{EARLY STUDIES}

In 1863, the German pathologist Nikolaus Friedreich described a new spinal disease, which turned out to be the first description of a hereditary ataxia ${ }^{1}$. The disease was characterized by cerebellar ataxia, dysarthria and deep areflexia, generally with an early age of onset and presenting an autosomal recessive pattern of inheritance ${ }^{1}$. Over 30 years later, Pierre Marie reported on a group of patients presenting with hereditary ataxia, but with late disease onset, mostly presenting with increased tendon reflexes and occasionally with an autosomal dominant pattern of inheritance ${ }^{2}$. It was later pointed out that Marie's cohort was both clinically and pathologically heterogeneous and several classifications throughout the $20^{\text {th }}$ century failed to outline properly the full clinical and pathological spectrum of the autosomal dominant cerebellar ataxias $(\mathrm{ADCA})^{3,4}$. The term spinocerebellar ataxia (SCA) remained from those early attempts to classify the $\mathrm{ADCA}$, and nowadays they are used as synonyms. Other terms previously used to describe ADCA were Marie's Ataxia, olivopontocerebellar atrophy and cerebello-olivary atrophy $\mathrm{y}^{24,5,6,7}$.

${ }^{1}$ Universidade de Campinas, Faculdade de Ciências Médicas, Departamento de Neurologia, Campinas SP, Brasil;

¿Universidade de Campinas, Faculdade de Ciências Médicas, Departamento de Genética Médica, Campinas SP, Brasil;

${ }^{3}$ Universidade Federal de São Paulo, Unidade de Ataxia, Departamento de Neurologia, São Paulo SP, Brasil.

Correspondence: Marcondes Cavalcante França Jr.; Departamento de Neurologia da UNICAMP; Rua Tessália Vieira de Camargo, 126 ; $13083-887$ Campinas SP, Brasil; E-mail: mcfrancajr@uol.com.br

Conflict of interest: There is no conflict of interest to declare.

Support: Fundação de Amparo à Pesquisa do Estado de São Paulo (FAPESP) (Grant \#13/01766-7 and \#2014/19786-7) and Coordenação de Aperfeiçoamento de Pessoal de Nivel Superior (CAPES).

Received 18 February 2018; Received in final form 27 May 2018; Accepted 04 June 2018. 


\section{HISTORY OF SCA1 GENETICS}

In the first half of the $20^{\text {th }}$ century, many researchers published papers on small families segregating ADCA, raising the most diverse hypotheses on the genetic basis of the disease, usually with conflicting results 5 . Nonetheless, in the late 1940s, a North American group started following a large family of patients $(n=342)$ in which 45 individuals presented with the disease. At that time, the authors attempted to determine the genetic basis of the disease using linkage analyses, but they failed to uncover the responsible gene/mutation ${ }^{8}$.

Despite the initial disappointing results, the investigators kept following these kindred. From the 1970s to the 1980s, strong evidence came out supporting that the causative gene of at least that form of ADCA was related to the HLA human complex. Further studies mapped the disease locus to the short arm of chromosome 6 . Finally, 100 years after Marie's original publication, in 1993, a collaborative study led by Zoghbi et al. was published, describing an unstable CAG trinucleotide repeat expansion at the coding region of the implicated gene as the first causative mutation of $\mathrm{ADCA}^{10}$. The normal SCA1 allele contained 6-38 CAG repeats interrupted by the CAT trinucleotide, in contrast with mutation carriers that had 39-44 continuous CAG repeats (Table 1). These authors also pointed out that the size of the repeat inversely correlated with the age of onset of the symptoms (anticipation phenomenon) $)^{10,11,12}$.

Other researchers such as Harry T. Orr and Sandro Banfi played key roles in the description and characterization of the ATXN1 gene ${ }^{10,13}$. The disease locus was named ATXN1 and those presenting with the mutation would thereafter be definitively classified as having SCA type $1^{4}$. Curiously, the gene related to Friedreich's ataxia was only described three years later. Hence, SCAl was indeed the first hereditary ataxia to have its genetic basis elucidated ${ }^{3,10,13}$.

The ATXN1 gene encodes a protein called ataxin 1, which has nuclear location inside neurons, but cytoplasmic location in other peripheral tissues. Mutation carriers produce an abnormal form of ataxin 1 with an excessive number of consecutive glutamine residues. Less than five years after the gene description, experimental studies with transgenic mice showed that the pathogenesis by which the mutation causes disease is a toxic gain of function ${ }^{4}$. Zoghbi's group then revealed the specific role of protein misfolding in the pathogenesis of SCA1, a finding that has proved relevant to

Table 1. ATXN1 allele ranges.

\begin{tabular}{lcc}
\hline Allele types & (CAG) repeat length & Penetrance \\
\hline Normal & $6-38 ; 39-44$ CAT interrupted & None \\
Intermediate & 44 CAT interrupted* & Partial
\end{tabular}

Expanded 39-44 CAGs uninterrupted; 45-91 Full

*A woman with 44 CAG repeats with CAT repeat interruptions had an affected father but was herself asymptomatic at age 66 years? other polyglutamine disorders ${ }^{14}$. After this, the group started looking at potential pharmacological interventions in animal models ${ }^{15}$.

\section{DEMOGRAPHIC DATA AND PHENOTYPIC CHARACTERIZATION}

The SCAs are rare diseases with prevalence rates ranging from 1-4 per 100,000 and SCA1 accounts for between 3\% and $16 \%$ of all autosomal dominant $\mathrm{SCAs}^{16}$. The search for relative frequencies of SCAs in Brazilian cohorts have shown that SCA1 represents $4.2 \%$ of all SCAs; generally, it is the $4^{\text {th }}$ or $5^{\text {th }}$ most frequent SCA, after SCA3, SCA2 and SCA7 $7^{17,18,19,20}$. The first descriptions of Brazilian patients with SCA1 are relatively recent. All patients attending our reference center in southeastern Brazil have descended from Italian immigrants $^{21}$. The relative frequencies of SCA1 patients in different populations are shown in Table $2^{22,23,24}$.

\section{Clinical aspects}

The up-to-date clinical description of SCA1 is a late-onset cerebellar syndrome, with ocular movement disturbances, in particular, hypermetric saccades, pyramidal or extrapyramidal signs and peripheral neuropathy ${ }^{3,4}$ A phenomenon of progressive worsening of the phenotype across generations has been observed previously ${ }^{4}$. The first symptoms often include gait disturbances, later followed by diplopia, dysarthric speech, uncoordinated handwriting and episodic vertigo. Patients may less commonly present with vocal cord abductor paralysis or psychosis. The average age of onset of SCA1 is between the third and fourth decades, but there is clear variability even within families. Survival from disease onset is around 15 years, but again there is remarkable variability (range 10 to 28 years) ${ }^{3.5}$.

In a recent series of Brazilian patients ${ }^{17}$, the most frequent clinical findings were, in descending order: ataxia (100\%), pyramidal findings (89\%), dysarthria and/or dysphagia (89\%), alterations in ocular movements (44\%), nystagmus (33\%), rigidity (33\%), palpebral retraction (22\%), sensory loss (11\%), dystonic movements (11\%), seizures (11\%). Absent reflexes, amyotrophy, visual loss, tremor and cognitive decline were not found.

Disease progression has recently been assessed in a large multicentric European study ${ }^{25}$. Authors found that SCA1 progresses faster than other types of SCAs, with a mean annual

Table 2. Relative frequency of SCA1 in different populations.

\begin{tabular}{lccc}
\hline Author $/$ Year & Country & $\begin{array}{c}\text { Cohort size } \\
(\mathrm{n})\end{array}$ & $\begin{array}{c}\text { Relative } \\
\text { frequency }\end{array}$ \\
\hline Filla et al 200022 & Italy & 116 families & $24 \%$ \\
Illarioshkin et al 1996 23 & Russia & 15 families & $33 \%$ \\
\hline Krysa et al 2016 24 & Poland & 203 families & $68 \%$ \\
de Castilhos et al 2014 & Brazil & 359 families & $4.2 \%$ \\
\hline
\end{tabular}


progression in ataxia score of 2.11 (Scale for the Assessment and Rating of Ataxia). Within the SCA1 group, patients who had a shorter duration of follow up, older age at initial evaluation and longer CAG repeats progressed at faster rates. It remains to be investigated whether such rates of progression also take place in SCA1 patients coming from other regions. Although ataxia is the main and most disabling symptom in most patients with SCA1, many have additional non-ataxia symptoms, which have a great impact on the quality of life of these patients.

\section{Cognitive impairment}

It is known that the cerebellum contributes to cognitive tasks, including executive and language functions ${ }^{26}$. In particular, patients with isolated acute or chronic focal cerebellar lesions show frontal-like and parietal-like symptoms; this clinical picture is referred to as the cerebellar cognitive affective syndrome ${ }^{26}$. The neuroanatomical basis for this syndrome is not fully clear, but at least two hypotheses have been raised: it may stem either from the interruption, as in a disconnection syndrome, or from a dysfunctional contribution of the cerebellum in the neocerebellar-neocortical reverberation network. This syndrome is characterized by impairments in executive functions (deficiency in planning, set-shifting, abstract reasoning, working memory, verbal fluency), language disorders, disturbances in spatial cognition, and personality changes ${ }^{26}$.

Several studies have reported the neuropsychological features of patients with SCA1, and most show impaired executive function, attention, visuospatial perception, verbal fluency, immediate and delayed memory ${ }^{27}$. Fancellu et al. reported that patients had significant deficits compared to controls, mainly in executive functions (phonemic and semantic fluencies, attentional matrices) and the dissociation in the progression of motor disability and cognitive impairments, suggesting that motor and cognitive functions might be related to different progression rates in $\mathrm{SCA}^{28}$.

Ma et al. reported that SCA1 causes mild impairment in executive function, temporal orientation and logical thinking. The cognitive deficits were correlated with clinical severity of ataxia symptoms, but not age, age of onset, years of education and disease duration ${ }^{29}$. Klinke et al. showed that asymptomatic SCA1 carriers have normal cognitive test scores, thus suggesting that cognitive dysfunction does not seem to precede cerebellar ataxia ${ }^{30}$. While some phenotypic traits, such as age of onset, progression rate and disease severity are directly related to genotype (CAG expansion length), it is unclear whether the occurrence and severity of cognitive impairment also depend on it. Moriarty et al. reported impairments in executive functions, speed, attention, visual memory and theory of mind in SCA1 patients. These authors also found SCA1 patients to have the fastest cognitive decline when compared with the other SCA patients, a finding in line with the motor deterioration pattern in $\mathrm{SCAs}^{30}$.
The pattern of alterations in executive and visuospatial functions described in $\mathrm{SCA}^{27}$ suggests a frontoparietal dysfunction that could be caused by an alteration in the frontoponto-cerebello-thalamo-cortical circuits ${ }^{26}$. A direct dysfunction of frontoparietal areas could be hypothesized; however, impairments in these cortical areas have not yet been proven in SCA1. In addition, the involvement of subcortical structures, such as the basal ganglia, could play a role in the development of cognitive dysfunction ${ }^{31}$.

\section{Depression}

Patients with cerebellar degenerative diseases have greater apathy, depression, anxiety and personality changes than normal individuals, especially when the cerebellar degeneration is associated with basal ganglia involvement ${ }^{26,27}$. It is hypothesized that these symptoms could be caused by a dysfunction in the connections between the prefrontal cortex (dorsolateral, orbitomedial, dorsomedial) and the basal ganglia ${ }^{32}$. Fancellu et al. reported that SCA1 patients had significantly higher depression scores and apathy than controls ${ }^{28}$. Klinke et al. showed a mildly depressed mood (Beck Depressive Inventory score 11-18) in 50\% of SCA1 patients, though no patient showed scores indicating a severely depressed mood (score $\geq 18)^{27}$. McMurtray et al. identified depressive and memory symptoms as heralding features of SCA1 in $25 \%$ and $42 \%$ of the patients, respectively ${ }^{33}$.

\section{Sleep disorders and fatigue}

Hypersomnolence in SCA1 patients can interfere with daytime functioning and periodic limb movements can be a cause of sleep fragmentation in these patients ${ }^{34}$. Obstructive sleep apnea can coexist with SCA1, possibly as a manifestation of pharyngeal dilator muscle incoordination in response to impending airway collapse ${ }^{34}$. According to Abele et al., restless legs syndrome is significantly more frequent in patients with SCA1 than in the general population and is present in $28 \%$ of patients ${ }^{35}$. Fatigue is a major manifestation in SCA1 patients and related to disease duration, depression and probably disease severity ${ }^{36}$.

\section{Electrophysiological features}

Multisystem involvement in SCA1 is common and electrophysiology is a potent tool to uncover impairment of multiple neuronal systems and even to decipher subclinical affective functions. Electrooculography reveals quantitatively abnormal eye movements, such as gaze-evoked nystagmus and slowing of saccades ${ }^{37}$. Visual-evoked potentials reveal decreased amplitude and/or prolonged latency of P100 wave $^{38}$. Abnormal acoustic-evoked potential findings include loss of waves as well as increased interpeak intervals ${ }^{38}$.

Somatosensory-evoked potentials also show impairment of central or peripheral sensory tracts in SCA1. Using somatosensory-evoked potentials, Abele et al. showed loss of P40 in 100\% of patients. Motor-evoked potentials are helpful 
to show subclinical affective functions of the corticospinal tracts, which is very frequent in $\mathrm{SCA}{ }^{38}$. Almost all patients presented with prolonged central motor conduction times and peripheral motor conduction times in all extremities ${ }^{38,39}$.

Nerve conduction studies reveal mildly reduced nerve conduction velocities in sensory and motor nerves, but amplitude reduction is much more prominent in sensory nerves than motor nerves ${ }^{39}$. Electromyography often reveals signs of chronic denervation affecting proximal and distal muscles. The pattern may resemble a distal neuropathy in some patients, but in others, it is much like a diffuse motor neuronopathy ${ }^{39}$. In a recent study, Linnemann et al. reported on the features of peripheral neuropathy in SCA1, in which mixed neuropathy was the most frequent pattern (83\%), followed by axonal (11\%) and demyelinating (6\%) disease ${ }^{40}$.

\section{Neuropathology}

Spinocerebellar ataxia type 1 is characterized macroscopically by olivoponto-cerebellar atrophy ${ }^{41}$. On microscopy, there is dramatic loss of cerebellar Purkinje cells as well as of neurons of the dentate nuclei, basal pontine and other brainstem areas, including the red nuclei, vestibular and motor cranial nerve nuclei ${ }^{41,42}$. In contrast, the pars compacta of the substantia nigra, the basal ganglia, thalamus, cerebral cortex and hippocampus are usually spared ${ }^{41}$. Hence, SCA1 neuropathology can involve components of the cerebello-thalamocortical loop, the basal ganglia-thalamocortical loop, the visual system and the somatosensory system ${ }^{43}$. The impairment of the spinal cord is conspicuous. It is characterized by gross atrophy, caused by loss of anterior horn cells, fibers in the posterior columns and neurons from the Clarke's column ${ }^{44}$.

\section{Neuroimaging}

Schulz et al. evaluated volumetric changes in SCA1 using voxel-based morphometry in a multicenter study with 48 patients. The authors reported gray matter volume loss in the cerebellar hemispheres, vermis, brainstem and white matter loss in the midbrain, pons, middle cerebellar peduncles, and cerebellar hemispheres. The brainstem and pons volumes correlated inversely with ataxia severity ${ }^{45}$.

Analyses of supratentorial structures revealed gray matter volume loss in the caudate nuclei, putamina and temporal lobes, but no correlations with clinical or molecular data were found ${ }^{45}$. In a two-year prospective study, Reetz et al. evaluated 37 patients with SCA1. Cross-sectional analyses found a significant decline in gray matter volume for the whole brainstem, left anterior and posterior cerebellum and the right putamen and pallidum compared to healthy controls. The length of the expanded CAG repeat allele correlated with cerebellum and pons volume loss in these patients. Longitudinal analyses identified progressive atrophy in the brainstem, pons, putamen, left caudate and left cerebellar hemisphere after two years. The length of the expanded CAG repeat allele correlated with the rate of cerebellar volume loss. In the same study, authors attempted to compare the rates of atrophy within different SCA subtypes. The SCA1 group indeed had an increased rate of volume loss in the whole brainstem, left cerebellar hemisphere, and putamen, when compared with the SCA3 group ${ }^{46}$.

Other studies using voxel-based morphometry also reported volume loss in the cerebellum and brainstem involving both gray and white matter ${ }^{47}$. Regional damage to cerebral white matter in individuals with SCA1 has repeatedly been demonstrated by diffusion tensor imaging in several studies ${ }^{48}$.

A multicenter observational European study, with 26 presymtomatic carriers of SCA1 mutations reported gray matter loss in the medulla oblongata extending to the pons and to the lobule IX of the cerebellum in these individuals compared with matched healthy controls. These results indicate that anatomical damage takes place before symptom onset in $\mathrm{SCAl}^{49}$. Patients with SCA1 also have cervical spinal cord atrophy combined with anteroposterior flattening $^{50}$. Interestingly, the spinal cord area correlates with ataxia severity, disease duration, and CAG expansion ${ }^{50}$.

Regarding neurochemical alterations detected by proton magnetic resonance spectroscopy, measurements of metabolites such as $\mathrm{N}$-acetylaspartate and myoinositol indicate neuronal loss in the cerebellum and pons in SCA1 patients. These parameters correlated with motor disability ${ }^{51}$. Figure 1 shows some aspects of imaging in SCA1.

\section{DISEASE MECHANISMS AND FUTURE THERAPEUTIC PERSPECTIVES}

Wild-type ATXN1 includes a polyQ tract that normally contains 6-34 glutamines. A monopartite nuclear-localization signal motif near the carboxyl terminus directs the localization of the protein to the nucleus ${ }^{52}$. ATXN1 containing a wild-type polyQ tract can move between the cytoplasm and nucleus inside neurons. On the other hand, ATXN1 containing an expanded polyQ tract is transported to the nucleus but cannot be exported to the cytoplasm $^{53}$. Such abnormal and obligatory localization inside the nucleus seems to be important for SCAl pathogenesis, since the substitution of a single amino acid within the nuclear-localization signal prevents the expanded ATXN1 from entering the cell nucleus and this mitigates its toxicity ${ }^{54}$.

Wild-type and expanded ATXN1 interact with various nuclear elements, such as $\mathrm{RNA}^{53,54}$, several regulators of transcription, capicua (CIC $)^{54}$, and others. An important approach to understanding SCA1 pathogenesis has been to model disease features in mice. The importance of ataxin1-CIC complexes in SCA1 pathogenesis is suggested by the observation that reducing CIC levels, either genetically or through exercise, decreases the deficit in motor performance and the premature lethality of the SCA1-like phenotypes in animal models ${ }^{55}$. 

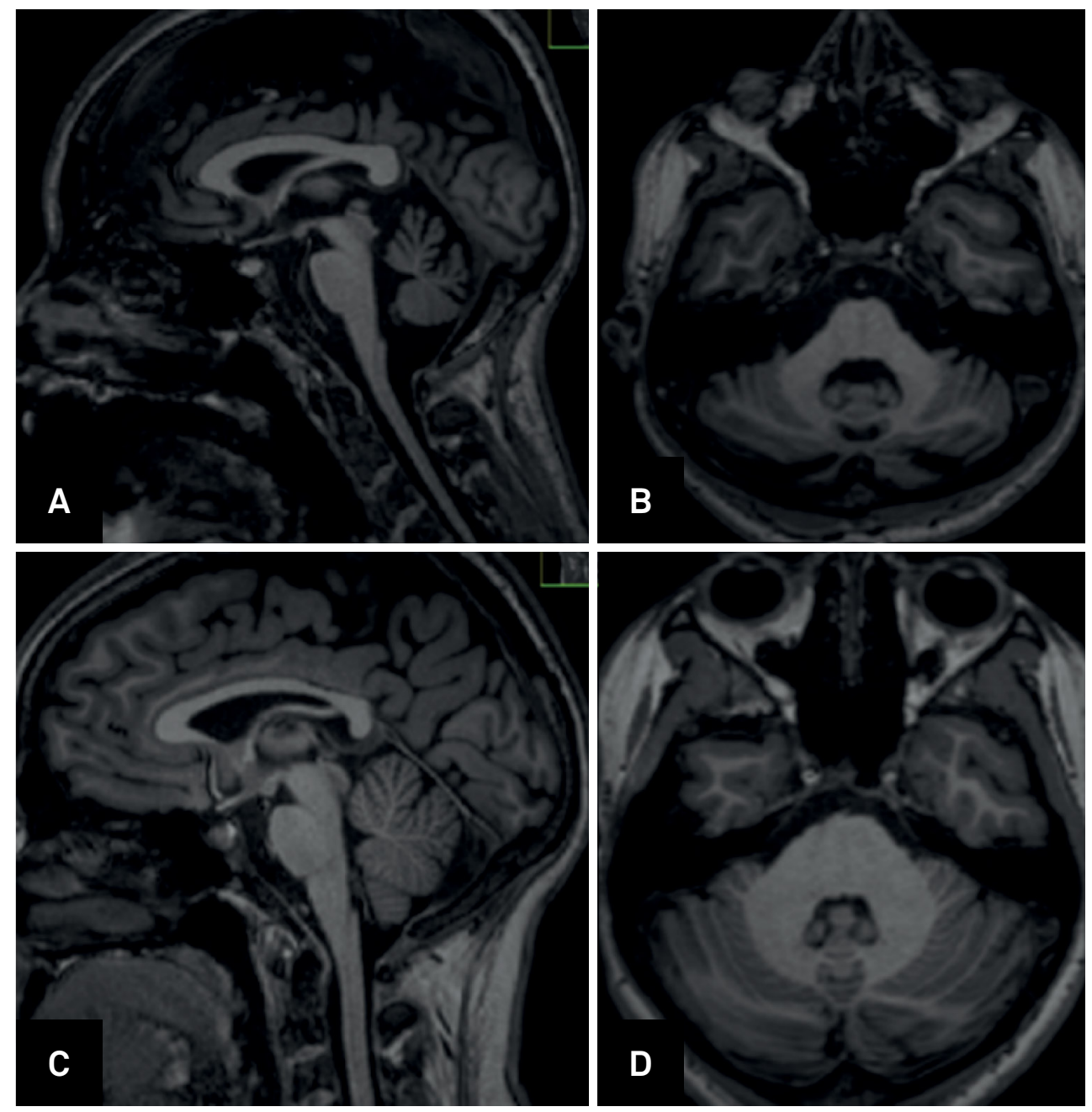

Figure 1. A. Sagittal T1-weighted brain MRI demonstrates cervical spinal cord atrophy in SCA1; B. Axial T1-weighted brain MRI shows moderate olivopontocerebellar atrophy in SCA1. C and D demonstrate spinal cord and brainstem in a healthy control.

On entering the nuclei of Purkinje cells, ataxin-1 binds to CIC. Although ataxin-1 alone does not bind to DNA ${ }^{54,55}$, the ataxin-1-CIC complex is targeted to chromatin and transcription sites, binding DNA. Noticeably, as transcription proceeds, ataxin- 1 is hypothesized to shuttle between complexes with CIC and the splicing factor RNA-binding motif protein (RBM)17. Ataxin-1 can be found in two high-molecular-weight soluble complexes: one that includes CIC and another that includes RBM17 ${ }^{55}$. These two ataxin- 1 complexes could be in a dynamic equilibrium and the dynamics of the complexes affect gene expression. An altered balance in the interaction of expanded ataxin-1 with CIC and RBM17 could drive pathogenesis in SCA1. In this way, expansion of the polyQ tract in ataxin-1 favors ataxin-1-RBM17 complex formation ${ }^{56}$, implicating this complex in SCAl pathogenesis (Figure 2).

Like other neurodegenerative disorders, such as Huntington disease ${ }^{57}$, mechanistic target of rapamycin (mTOR) signaling is altered in SCA1. In the cerebellar proteomes of transgenic mice with ataxin-1[82Q]-expressing Purkinje cells, mTOR levels were decreased before the onset of symptoms ${ }^{58}$. The DNA-damage and DNA-repair pathways have also been implicated in the pathogenesis of $\mathrm{SCA}^{59}$. In Sca1154Q/2Q mice, enhanced expression of proteins that function in several DNA-repair pathways and restoration of mitochondrial DNA repair by expressing the DNA-repair protein ${ }^{60}$, could improve motor performance, Purkinje cell morphology, molecular functions and attenuate SCA1-like phenotypes.

Furthermore, early changes in the expression of specific receptors and ion channels that are important for regulating membrane excitability, such as the dysregulation of calcium-activated potassium channel physiology, contribute not only to motor dysfunction but also to structural changes in neurons that consistently precede cell death, changing the intrinsic excitability of Purkinje neurons ${ }^{61}$.

Several aspects of SCA1 pathogenesis still remain unclear 25 years after the gene/mutation description. Moreover, the studies have shown that long polyglutamine tracts expressed by the mutated gene have an increased tendency to aggregate, creating nuclear inclusion bodies in affected neurons that are ubiquitinated ${ }^{3,4}$. Screening is in progress to find polyQ 


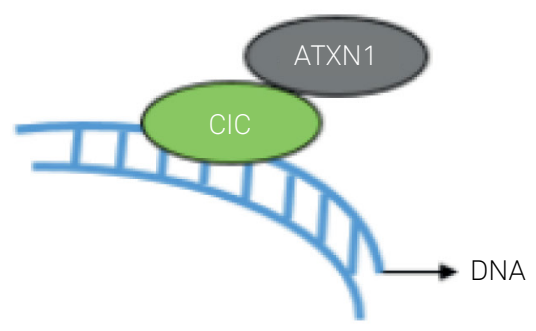

Transcription

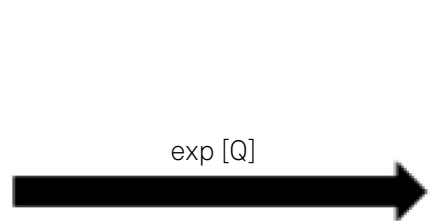

RNA splicing

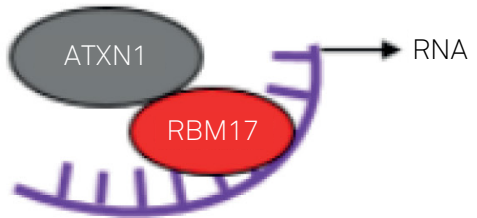

Nucleus

Figure 2. Illustration of a model of SCA1 pathogenesis that incorporates the crucial nuclear interactions and functions of ATXN1. On entering the nuclei of Purkinje cells, ATXN1 readily binds to CIC (transcriptional regulator capicua). Although ATXN1 alone does not bind to DNA, CIC can bind DNA. ATXN1 can be found in two high-molecular-weight soluble complexes: one that includes CIC and another, distinct complex that includes RBM17 (RNA splicing factor). Importantly, expansion of the polyQ tract in ATXN1 favors ATXN1-RBM17 complex formation, implicating this complex in SCA1 pathogenesis. PolyQ expansion is depicted by ‘exp[Q]'

aggregate inhibitors and also to check whether silencing gene expression can be an interesting therapeutic option ${ }^{3,4}$. However, as described above, several cellular pathways are implicated in SCA1 pathogenesis and this multipathway picture makes the development of new therapies difficult. To date, there is no curative treatment for SCA1. Nevertheless, symptomatic therapy may ameliorate symptoms, especially the nonmotor aspects, like depression and sleep disorders.

There are several lines of research on therapeutic agents for SCA1, usually based on animal and cell-based models. Given that mutant polyQ disease proteins can disturb gene expression, RNA homeostasis and protein homeostasis through diverse pathways with largely downstream consequences, acting proximally in the disease cascade to lower the levels of the toxic protein can be a useful strategy towards developing a disease-modifying therapy. In this sense, endeavors to target the expression of polyQ SCA proteins have used antisense oligonucleotides or virus-mediated delivery of short hairpin RNAs or artificial miRNAs to interfere with translation. Preclinical tests of antisense oligonucleotides or miRNA-based drugs for $\mathrm{SCA}^{56}$ show considerable promise, making clinical trials increasingly likely.

Experimental data suggested that lithium treatment improves motor coordination and multiple behavioral measures, and might lead to neuroprotective properties in the cerebellum of SCA1 mouse models ${ }^{63}$. Based on this, lithium could be a potential treatment for human SCA1. A Phase I trial of oral lithium has been completed as an intramural National Institutes of Health study, but results have not yet been published (NCT00683943). Riluzole has been shown to provide some symptomatic relief of ataxia in a mixed group of individuals including people with SCA1 ${ }^{64}$; however, further investigation is needed, particularly long-term disease-specific trials. A double-blind randomized placebo controlled trial of a riluzole prodrug BHV4157 is ongoing (NCT02960893).

In line with other therapies, Matsuura et al. reported that intrathecal injection of mesenchymal stem cells into the meningeal covering of the cerebellum improved Purkinje cell organization, reduced cerebellar dendrite atrophy and normalized behavior and motor deficits in B05 mice injected at five weeks of age ${ }^{65}$. Thus, further investigation is needed to confirm the therapeutic potential of stem cells in SCA1. Gene therapy is based on reducing expression of the mutant ATXN1 through gene silencing or overexpressing a paralog of $A T X N 1$, ataxin-1like (ATXN1L), to competitively inhibit the formation of toxic complexes by polyQ-ataxin- ${ }^{66}$. This approach appears to be promising, but further clinical studies are still needed.

In conclusion, in over 100 years of research, there is still a long way to fully understanding and treating patients diagnosed with SCA1. Nevertheless, recent progress and the genetic outbreaks of the 1990s have given neurologists and neuroscientists valuable hints on where to search for answers.

\section{References}

1. Friedreich, N. Ueber degenerative Atrophie der spinalen Hinterstränge. Arch Pathol Anat Physiol KlinMed. 1863;26:391-419.

2. Marie P. La semaine médicale: sur l'hérédo-ataxie cérébelleuse. Semaine Médicale. 1893.

3. Finsterer J. Ataxias with autosomal, X-chromosomal or maternal inheritance. Can J Neurol Sci. 2009 Jul;36(4):409-28. https://doi.org/10.1017/S0317167100007733

4. Cummings CJ, Orr HT, Zoghbi HY. Progress in pathogenesis studies of spinocerebellar ataxia type 1. Philos Trans R Soc Lond B Biol Sci. 1999 Jun;354(1386):1079-81. https://doi.org/10.1098/rstb.1999.0462
5. Schut JW. Hereditary ataxia: clinical study through six generations. Arch NeurPsych. 1950;63(4):535-68. https://doi.org/10.1001/archneurpsyc.1950.02310220002001

6. Konigsmark BW, Weiner LP. The olivopontocerebellar atrophies: a review. Medicine (Baltimore). 1970 May;49(3):227-41. https://doi.org/10.1097/00005792-197005000-00003

7. Harding AE. The clinical features and classification of the late onset autosomal dominant cerebellar ataxias: a study of 11 families, including descendants of the 'the Drew family of Walworth'. Brain. 1982 Mar;105(Pt 1):1-28. https://doi.org/10.1093/brain/105.1.1 
8. Matson GA, Schut JW, Swanson J. Hereditary ataxia: linkage studies in hereditary ataxia. Ann Hum Genet. 1961 May;25(1):7-23. https://doi.org/10.1111/j.1469-1809.1961.tb01492.x

9. Rich SS, Wilkie P, Schut L, Vance G, Orr HT. Spinocerebellar ataxia: localization of an autosomal dominant locus between two markers on human chromosome 6. Am J Hum Genet. 1987 Oct;41(4):524-31.

10. Orr HT, Chung MY, Banfi S, Kwiatkowski TJ Jr, Servadio A, Beaudet AL et al. Expansion of an unstable trinucleotide CAG repeat in spinocerebellar ataxia type 1. Nat Genet. $1993 \mathrm{Jul}$;4(3):221-6. https://doi.org/10.1038/ng0793-221

11. Goldfarb LG, Vasconcelos O, Platonov FA, Lunkes A, Kipnis V, Kononova $S$ et al. Unstable triplet repeat and phenotypic variability of spinocerebellar ataxia type 1. Ann Neurol. 1996 Apr;39(4):500-6. https://doi.org/10.1002/ana.410390412

12. Zühlke C, Dalski A, Hellenbroich Y, Bubel S, Schwinger E, Bürk K. Spinocerebellar ataxia type 1 (SCA1): phenotype-genotype correlation studies in intermediate alleles. Eur J Hum Genet. 2002;10(3):204-9. https://doi.org/10.1038/sj.ejhg.5200788

13. Banfi S, Servadio A, Chung MY, Kwiatkowski TJ Jr, McCall AE, Duvick LA et al. Identification and characterization of the gene causing type 1 spinocerebellar ataxia. Nat Genet. 1994 Aug;7(4):513-20. https://doi.org/10.1038/ng0894-513

14. Cummings CJ, Mancini MA, Antalffy B, DeFranco DB, Orr HT, Zoghbi HY. Chaperone suppression of aggregation and altered subcellular proteasome localization imply protein misfolding in SCA1. Nat Genet. 1998 Jun;19(2):148-54. https://doi.org/10.1038/502

15. Emamian ES, Kaytor MD, Duvick LA, Zu T, Tousey SK, Zoghbi HY et al. Serine 776 of ataxin-1 is critical for polyglutamine-induced disease in SCA1 transgenic mice. Neuron. 2003 May;38(3):375-87. https://doi.org/10.1016/S0896-6273(03)00258-7

16. Manto M, Marmolino D. Cerebellar ataxias. Curr Opin Neurol. 2009 Aug;22(4):419-29. https://doi.org/10.1097/WC0.0b013e32832b9897

17. Castilhos RM, Furtado GV, Gheno TC, Schaeffer P, Russo A, Barsottin $O$ et al. Rede Neurogenetica. Spinocerebellar ataxias in Brazil: frequencies and modulating effects of related genes. Cerebellum. 2014 Feb;13(1):17-28. https://doi.org/10.1007/s12311-013-0510-y

18. Silveira I, Lopes-Cendes I, Kish S, Maciel P, Gaspar C, Coutinho P et al. Frequency of spinocerebellar ataxia type 1, dentatorubropallidoluysian atrophy, and Machado-Joseph disease mutations in a large group of spinocerebellar ataxia patients. Neurology. 1996 Jan;46(1):214-8. https://doi.org/10.1212/WNL.46.1.214

19. Trott A, Jardim LB, Ludwig HT, Saute JA, Artigalás O, Kieling C et al. Spinocerebellar ataxias in 114 Brazilian families: clinical and molecular findings. Clin Genet. 2006 Aug;70(2):173-6. https://doi.org/10.1111/j.1399-0004.2006.00656.x

20. Teive HA, Munhoz RP, Arruda WO, Lopes-Cendes I, Raskin S, Werneck LC et al. Spinocerebellar ataxias: genotype-phenotype correlations in 104 Brazilian families. Clinics (São Paulo). 2012;67(5):443-9. https://doi.org/10.6061/clinics/2012(05)07

21. Lopes-Cendes I, Steiner CE, Silveira I, Pinto Júnior W, Maciel JA, Rouleau GA. Clinical and molecular characteristics of a Brazilian family with spinocerebellar ataxia type 1. Arq Neuropsiquiatr. 1996 Sep;54(3):412-8. https://doi.org/10.1590/S0004-282X1996000300009

22. Filla A, Mariotti C, Caruso G, Coppola G, Cocozza S, Castaldo I et al. Relative frequencies of CAG expansions in spinocerebellar ataxia and dentatorubropallidoluysian atrophy in 116 Italian families. Eur Neurol. 2000;44(1):31-6. https://doi.org/10.1159/000008189

23. Illarioshkin SN, Slominsky PA, Ovchinnikov IV, Markova ED, Miklina NI, Klyushnikov SA et al. Spinocerebellar ataxia type 1 in Russia. J Neurol. 1996 Jul;243(7):506-10. https://doi.org/10.1007/BF00886871

24. Krysa W, Sulek A, Rakowicz M, Szirkowiec W, Zaremba J. High relative frequency of SCA1 in Poland reflecting a potential founder effect. Neurol Sci. 2016 Aug;37(8):1319-25. https://doi.org/10.1007/s10072-016-2594-X

25. Jacobi H, Montcel ST, Bauer P, Giunti P, Cook A, Labrum R et al. Longterm disease progression in spinocerebellar ataxia types 1, 2, 3, and
6: a longitudinal cohort study. Lancet Neurol. 2015 Nov;14(11):11018. https://doi.org/10.1016/S1474-4422(15)00202-1

26. Schmahmann JD, Sherman JC. The cerebellar cognitive affective syndrome. Brain. 1998 Apr;121(Pt 4):561-79. https://doi.org/10.1093/brain/121.4.561

27. Klinke I, Minnerop M, Schmitz-Hübsch T, Hendriks M, Klockgether T, Wüllner $U$ et al. Neuropsychological features of patients with spinocerebellar ataxia (SCA) types 1, 2, 3, and 6. Cerebellum. 2010 Sep;9(3):433-42. https://doi.org/10.1007/s12311-010-0183-8

28. Fancellu R, Paridi D, Tomasello C, Panzeri M, Castaldo A, Genitrini S et al. Longitudinal study of cognitive and psychiatric functions in spinocerebellar ataxia types 1 and 2. J Neurol. 2013 Dec;260(12):3134-43. https://doi.org/10.1007/s00415-013-7138-1

29. Ma J, Wu C, Lei J, Zhang X. Cognitive impairments in patients with spinocerebellar ataxia types 1,2 and 3 are positively correlated to the clinical severity of ataxia symptoms. Int J Clin Exp Med. 2014 Dec;7(12):5765-71.

30. Moriarty A, Cook A, Hunt H, Adams ME, Cipolotti L, Giunti P. A longitudinal investigation into cognition and disease progression in spinocerebellar ataxia types 1, 2, 3, 6, and 7. Orphanet J Rare Dis. 2016 Jun;11(1):82. https://doi.org/10.1186/s13023-016-0447-6

31. Jacobi H, Hauser TK, Giunti P, Globas C, Bauer P, Schmitz-Hübsch T et al. Spinocerebellar ataxia types 1,2,3 and 6: the clinical spectrum of ataxia and morphometric brainstem and cerebellar findings. Cerebellum. 2012 Mar;11(1):155-66. https://doi.org/10.1007/s12311-011-0292-z

32. Leroi I, O'Hearn E, Marsh L, Lyketsos CG, Rosenblatt A, Ross CA et al. Psychopathology in patients with degenerative cerebellar diseases: a comparison to Huntington's disease. Am J Psychiatry. 2002 Aug;159(8):1306-14. https://doi.org/10.1176/appi.ajp.159.8.1306

33. McMurtray AM, Clark DG, Flood MK, Perlman S, Mendez MF. Depressive and memory symptoms as presenting features of spinocerebellar ataxia.J Neuropsychiatry Clin Neurosci. 2006;18(3):420-2. https://doi.org/10.1176/jnp.2006.18.3.420

34. Dang D, Cunnington D. Excessive daytime somnolence in spinocerebellar ataxia type 1. J Neurol Sci. 2010 Mar;290(1-2):146-7. https://doi.org/10.1016/j.jns.2009.12.007

35. Abele M, Bürk K, Laccone F, Dichgans J, Klockgether T. Restless legs syndrome in spinocerebellar ataxia types 1, 2, and 3.J Neurol. 2001 Apr;248(4):311-4. https://doi.org/10.1007/s004150170206

36. Martins CR Jr, Martinez AR, D’Abreu A, Lopes-Cendes I, França Junior MC. Fatigue is frequent and severe in spinocerebellar ataxia type 1. Parkinsonism Relat Disord. 2015 Jul;21(7):821-2. https://doi.org/10.1016/j.parkreldis.2015.04.015

37. Buttner N, Geschwind D, Jen JC, Perlman S, Pulst SM, Baloh RW. Oculomotor phenotypes in autosomal dominant ataxias. Arch Neurol. 1998 Oct;55(10):1353-7. https://doi.org/10.1001/archneur.55.10.1353

38. Abele M, Bürk K, Andres F, Topka H, Laccone F, Bösch S et al. Autosomal dominant cerebellar ataxia type I. Nerve conduction and evoked potential studies in families with SCA1, SCA2 and SCA3. Brain. 1997 Dec;120(Pt 12):2141-8. https://doi.org/10.1093/brain/120.12.2141

39. Warrenburg BP, Notermans NC, Schelhaas HJ, Alfen N, Sinke RJ, Knoers NV et al. Peripheral nerve involvement in spinocerebellar ataxias. Arch Neurol. 2004 Feb;61(2):257-61. https://doi.org/10.1001/archneur.61.2.257

40. Linnemann C, Montcel ST, Rakowicz M, Schmitz-Hübsch T, Szymanski S, Berciano J et al. Peripheral Neuropathy in Spinocerebellar Ataxia Type 1, 2, 3, and 6. Cerebellum. 2016 Apr;15(2):165-73. https://doi.org/10.1007/s12311-015-0684-6

41. Globas C, Montcel ST, Baliko L, Boesch S, Depondt C, DiDonato S et al. Early symptoms in spinocerebellar ataxia type 1, 2, 3, and 6. Mov Disord. 2008 Nov;23(15):2232-8. https://doi.org/10.1002/mds.22288

42. Schut JW, Haymaker W. Hereditary ataxia: a pathologic study of five cases of common ancestry. J Neuropathol Clin Neurol. 1951 Jul;1(3):183-213. 
43. Rüb U, Schöls L, Paulson H, Auburger G, Kermer P, Jen JC et al. Clinical features, neurogenetics and neuropathology of the polyglutamine spinocerebellar ataxias type 1, 2, 3, 6 and 7. Prog Neurobiol. 2013;104:38-66. https://doi.org/10.1016/j.pneurobio.2013.01.001

44. Iwabuchi K, Tsuchiya K, Uchihara T, Yagishita S. Autosomal dominant spinocerebellar degenerations. Clinical, pathological, and genetic correlations. Rev Neurol (Paris). 1999 Apr;155(4):255-70.

45. SchulzJB, BorkertJ, Wolf S, Schmitz-Hübsch T, Rakowicz M, Mariotti C et al.Visualization, quantification and correlation of brain atrophy with clinical symptoms in spinocerebellar ataxia types 1,3 and 6. Neuroimage. 2010 Jan;49(1):158-68. https://doi.org/10.1016/j.neuroimage.2009.07.027

46. Reetz K, Costa AS, Mirzazade S, Lehmann A, Juzek A, Rakowicz M et al. Genotype-specific patterns of atrophy progression are more sensitive than clinical decline in SCA1, SCA3 and SCA6. Brain. 2013 Mar;136(Pt 3):905-17. https://doi.org/10.1093/brain/aws369

47. Guerrini L, Lolli F, Ginestroni A, Belli G, Della Nave R, Tessa C et al. Brainstem neurodegeneration correlates with clinical dysfunction in SCA1 but not in SCA2. A quantitative volumetric, diffusion and proton spectroscopy MR study. Brain. 2004 Aug;127(Pt 8):1785-95. https://doi.org/10.1093/brain/awh201

48. Della Nave R, Ginestroni A, Tessa C, Salvatore E, De Grandis D, Plasmati R et al. Brain white matter damage in SCA1 and SCA2. An in vivo study using voxel-based morphometry, histogram analysis of mean diffusivity and tract-based spatial statistics. Neuroimage. 2008 Oct;43(1):10-9. https://doi.org/10.1016/j.neuroimage.2008.06.036

49. Jacobi H, Reetz K, Montcel ST, Bauer P, Mariotti C, Nanetti L et al. Biological and clinical characteristics of individuals at risk for spinocerebellar ataxia types 1, 2, 3, and 6 in the longitudinal RISCA study: analysis of baseline data. Lancet Neurol. 2013 Jul;12(7):650-8. https://doi.org/10.1016/S1474-4422(13)70104-2

50. Martins Junior CR, Martinez AR, Rezende TJ, Branco LM, Pedroso JL, Barsottini OG et al. Spinal cord damage in spinocerebellar ataxia type 1. Cerebellum. 2017 Aug;16(4):792-6. https://doi.org/10.1007/s12311-017-0854-9

51. Oz G, Hutter D, Tkác I, Clark HB, Gross MD, Jiang H et al. Neurochemical alterations in spinocerebellar ataxia type 1 and their correlations with clinical status. Mov Disord. 2010 Jul;25(9):1253-61. https://doi.org/10.1002/mds.23067

52. Klement IA, Skinner PJ, Kaytor MD, Yi H, Hersch SM, Clark HB et al. Ataxin-1 nuclear localization and aggregation: role in polyglutamineinduced disease in SCA1 transgenic mice. Cell. 1998 Oct;95(1):41-53. https://doi.org/10.1016/S0092-8674(00)81781-X

53. Irwin S, Vandelft M, Pinchev D, Howell JL, Graczyk J, Orr HT et al. RNA association and nucleocytoplasmic shuttling by ataxin-1.J Cell Sci. 2005 Jan;118(Pt 1):233-42. https://doi.org/10.1242/jcs.01611

54. Yue S, Serra HG, Zoghbi HY, Orr HT. The spinocerebellar ataxia type 1 protein, ataxin-1, has RNA-binding activity that is inversely affected by the length of its polyglutamine tract. Hum Mol Genet. 2001 Jan;10(1):25-30. https://doi.org/10.1093/hmg/10.1.25
55. Fryer JD, Yu P, Kang H, Mandel-Brehm C, Carter AN, Crespo-Barreto $J$ et al. Exercise and genetic rescue of SCA1 via the transcriptional repressor Capicua. Science. 2011 Nov;334(6056):690-3. https://doi.org/10.1126/science.1212673

56. Lim J, Crespo-Barreto J, Jafar-Nejad P, Bowman AB, Richman R, Hill DE et al. Opposing effects of polyglutamine expansion on native protein complexes contribute to SCA1. Nature. 2008 Apr;452(7188):713-8. https://doi.org/10.1038/nature06731

57. Lee JH, Tecedor L, Chen YH, Monteys AM, Sowada MJ, Thompson LM et al. Reinstating aberrant mTORC1 activity in Huntington's disease mice improves disease phenotypes. Neuron. 2015 Jan;85(2):303-15. https://doi.org/10.1016/j.neuron.2014.12.019

58. Sánchez I, Balagué E, Matilla-Dueñas A. Ataxin-1 regulates the cerebellar bioenergetics proteome through the GSK3 $\beta$-mTOR pathway which is altered in Spinocerebellar ataxia type 1 (SCA1). Hum Mol Genet. 2016 Sep;25(18):4021-40. https://doi.org/10.1093/hmg/ddw242

59. Bettencourt C, Hensman-Moss D, Flower M, Wiethoff S, Brice A, Goizet $C$ et al. DNA repair pathways underlie a common genetic mechanism modulating onset in polyglutamine diseases. Ann Neurol. 2016 Jun;79(6):983-90. https://doi.org/10.1002/ana.24656 PMID:27044000

60. Taniguchi JB, Kondo K, Fujita K, Chen X, Homma H, Sudo T et al. RpA1 ameliorates symptoms of mutant ataxin-1 knock-in mice and enhances DNA damage repair. Hum Mol Genet. 2016 Oct;25(20):4432-47. https://doi.org/10.1093/hmg/ddw272

61. Hourez R, Servais L, Orduz D, Gall D, Millard I, Exaerde AK et al. Aminopyridines correct early dysfunction and delay neurodegeneration in a mouse model of spinocerebellar ataxia type 1.J Neurosci. 2011 Aug;31(33):11795-807. https://doi.org/10.1523/JNEUROSCI.0905-11.2011

62. Miyazaki Y, Du X, Muramatsu S, Gomez CM. An miRNA-mediated therapy for SCA6 blocks IRES-driven translation of the CACNA1A second cistron. Sci Transl Med. 2016 Jul;8(347):347ra94. https://doi. org/10.1126/scitranslmed.aaf5660

63. Watase K, Gatchel JR, Sun Y, Emamian E, Atkinson R, Richman $R$ et al. Lithium therapy improves neurological function and hippocampal dendritic arborization in a spinocerebellar ataxia type 1 mouse model. PLoS Med. 2007 May;4(5):e182. https://doi.org/10.1371/journal.pmed.0040182

64. Romano S, Coarelli G, Marcotulli C, Leonardi L, Piccolo F, Spadaro M et al. Riluzole in patients with hereditary cerebellar ataxia: a randomised, double-blind, placebo-controlled trial. Lancet Neurol. 2015 Oct;14(10):985-91. https://doi.org/10.1016/S1474-4422(15)00201-X

65. Matsuura S, Shuvaev AN, lizuka A, Nakamura K, Hirai H. Mesenchymal stem cells ameliorate cerebellar pathology in a mouse model of spinocerebellar ataxia type 1. Cerebellum. 2014 Jun;13(3):323-30. https://doi.org/10.1007/s12311-013-0536-1

66. Keiser MS, Boudreau RL, Davidson BL. Broad therapeutic benefit after RNAi expression vector delivery to deep cerebellar nuclei: implications for spinocerebellar ataxia type 1 therapy. Mol Ther. 2014 Mar;22(3):588-95. https://doi.org/10.1038/mt.2013.279 